\title{
NILAI-NILAI PENDIDIKAN PUASA RAMADAN DALAM KOMIK WEBTOON NOSTALGIA RAMADHAN SI JUKI KECIL KARYA FAZA MEONK
}

\section{EDUCATIONAL VALUES OF RAMADAN FASTING IN THE WEBTOON COMIC NOSTALGIA RAMADHAN SI JUKI KECIL BY FAZA MEONK}

\author{
Rudi, Noviatussa'diyah \\ Universitas Muhammadiyah Malang \\ Ponsel: 081216835901; Pos-el: rudikisara15@gmail.com
}

\begin{abstract}
Abstrak
Nilai-nilai pendidikan puasa Ramadan dalam kehidupan manusia sangat esensial. Ibadah puasa Ramadan dapat meningkatkan kecerdasan spiritual seseorang, dan memperbaiki hubungan kepada Allah dan sesama. Adapun tujuan artikel ini adalah mendeskripsikan nilai-nilai pendidikan puasa Ramadan dalam komik webtoon "Nostalgia Ramadhan Si Juki Kecil" karya Faza Meonk. Metode yang digunakan dalam artikel ini adalah analisis isi kualitatif. Sumber data artikel ini adalah komik webtoon "Nostalgia Ramadhan Si Juki Kecil" karya Faza Meonk. Data berupa kalimat dan dialog yang menggambarkan nilai-nilai pendidikan puasa Ramadan. Teknik pengumpulan data dengan cara sebagai berikut, (1) membaca secara keseluruhan teks cerita komik "Nostalgia Ramadhan Si Juki Kecil" karya Faza Meonk, (2) mengidentifikasi data yang mencerminkan nilai-nilai pendidikan puasa Ramadan, dan (3) mencatat data yang diperoleh dari komik webtoon "Nostalgia Ramadhan Si Juki Kecil" karya Faza Meonk. Adapun teknik analisa data yang dilakukan dalam artikel ini yaitu, (1) mengklasifikasi data sesuai dengan rumusan masalah, (2) menganalisis data, (3) menginterpretasikan data, dan (4) penarikan kesimpulan. Hasil artikel menunjukkan nilai-nilai pendidikan puasa Ramadan dalam komik webtoon "Nostalgia Ramadhan Si Juki Kecil" karya Faza Meonk adalah sebagai berikut. (1) Nilai pendidikan puasa Ramadan dalam aspek kejujuran, dapat dilihat pada pelaksanaan puasa yaitu takut melakukan perbuatan mencuri dan keberanian sebagai bentuk kejujuran. (2) Nilai pendidikan puasa Ramadan dalam aspek kedisiplinan, terdapat pada kegiatan sahur dan buka puasa dan kegiatan pesantren kilat di masjid. (3) Nilai
\end{abstract}


pendidikan puasa Ramadan dalam aspek kepekaan sosial, terdapat pada kegiatan ngabuburit dan kegiatan salat id dan silaturahmi.

Kata kunci: komik webtoon; sastra; nilai pendidikan; puasa Ramadan

\begin{abstract}
The educational values of Ramadan fasting are very important for human life. Ramadan fasting can improve one's spiritual intelligence and the relationship with the God and other humas. The purpose of this study is to describe the educational values of Ramadan fasting in the webtoon comic "Nostalgia Ramadhan Si Juki Kecil" written by Faza Meonk. The method used in this article is qualitative content analysis. The data source of this article is the comic webtoon "Nostalgia Ramadhan Si Juki Kecil" by Faza Meonk. The data are in the form of sentences and dialogs that describe the educational values of Ramadan fasting. The data ate collected through the techniques as follows, (1) reading the entire text of the comic story "Nostalgia Ramadhan Si Juki Kecil" by Faza Meonk, (2) identifying data that reflects the educational values of Ramadan fasting education, and (3) recording the data obtained from the webtoon comic "Nostalgia Ramadhan Si Juki Kecil" by Faza Meonk. The data analysis technique used in this article is, (1) classifying data according to the formulation of the problem, (2) analyzing data, (3) interpreting data, and (4) drawing conclusions. Results of this study showing the educational values of Ramadan fasting in the webtoon comic "Nostalgia Ramadhan Si Juki Kecil" by Faza Meonk are as follows. (1) The educational values of Ramadan fasting cocerning honesty as found in the implementation of fasting, namely the fear of stealing and courage as a form of honesty. (2) The educational values of Ramadan fasting cocerning discipline as found in the activities of dawn-meal, breaking fast and pesantren kilat in the mosque. (3) The educational values of Ramadan fasting cocerning social sensitivity as found in ngabuburit and Id prayer activities and hospitality.
\end{abstract}

Keywords: webtoon comics; literature; Ramadan fasting; educationional values 


\section{Pendahuluan}

Hakikat pendidikan dalam kehidupan sangat penting untuk membawa peradaban manusia ke arah yang unggul dan berkualitas. Menurut John Dewey (Syafril \& Zen, 2019:28) memaknai pendidikan sebagai upaya yang dilakukan manusia untuk membentuk kecakapan fundamental dalam aspek emosional dan intelektual yang berguna untuk kehidupan seharihari. Sementara dari perspektif Ki Hajar Dewantara (Sukiyat, 2020:38), hakikat pendidikan merupakan upaya pembentukan budi pekerti, intelektual, dan jasmani anak agar dapat memajukan kesempurnaan hidup yang sesuai dengan alam dan masyarakat. Adapun pendidikan menurut Al-Qur'an dalam tafsir H.M. Quraish Shihab (Nata, 2016: 8), pendidikan bertujuan sebagai upaya membina manusia untuk menjalankan kehidupan sesuai dengan perintah Allah.

Pendidikan memiliki relevansi dengan karya sastra. Melalui karya sastra, dapat dilihat fenomena pendidikan yang terjadi dewasa ini. Salah satunya adalah menurunnya nilainilai pendidikan agama di dalam masyarakat. Degradasi nilai-nilai pendidikan agama dapat dilihat dari maraknya kriminalitas moral di masyarakat, salah satunya adalah kasus youtuber yang bersedekah batu bata dan sampah di bulan puasa Ramadan (Gunandha \& Aditya, 2020). Oleh karena itu, artikel ini sangat penting untuk melihat nilai-nilai pendidikan agama dalam karya sastra dan dapat mengedukasi pembaca/masyarakat untuk meningkatkan kecerdasan spiritual yang berkualitas.

Karya sastra merupakan hasil reka cipta pengarang berdasarkan rekaman peristiwa dalam kehidupannya. Dalam reka cipta karya sastra, pengarang menggunakan bahasa sebagai media untuk menggambarkan potret realitas (Ardias, Sumartini, \& Mulyono, 2019: 49). Karya sastra memiliki nilai estetik yang berfungsi sebagai hiburan dan edukasi nilai kehidupan kepada pembaca/masyarakat. Karya sastra dapat dinikmati oleh semua kalangan, mulai dari anak-anak, orang dewasa, dan orang tua.

Dinamika karya sastra seiring perkembangan teknologi membawa warna terhadap karya sastra. Salah satu produk dari karya sastra berbentuk prosa adalah komik (Setyawan, 2018: 1). Komik merupakan karya sastra yang diciptakan berdasarkan imajinasi pengarang berbentuk gambar dan teks 
yang mengandung makna (Putri, 2016:

1). Makna dalam komik seperti pendidikan, budaya, dan nilai kehidupan yang bertujuan memberikan edukasi kepada pembaca. Oleh karena itu, karya sastra dewasa ini, tidak hanya terfokus kepada bahasa, melainkan dapat dikombinasikan dengan gambar yang menunjang terhadap pembaca untuk memahami makna dalam karya sastra.

Di Indonesia komik sudah lama dikenal oleh masyarakat. Adanya komik tersebut mendapat sambutan yang baik di kalangan pembaca. Pembaca juga dapat mengakses komik secara digital, salah satunya adalah melalui line webtoon. Webtoon sendiri merupakan komik yang berasal dari Korea Selatan. Webtoon menawarkan kumpulan komik yang mengandung tema dan alur cerita menarik, seperti nilai-nilai pendidikan keagamaan.

Salah satu komik webtoon yang mengandung nilai-nilai pendidikan agama adalah serial komik "Nostalgia Ramadhan Si Juki Kecil" karya Faza Meonk. Komik ini menceritakan sebuah memori tokoh Juki saat menjalan ibadah puasa Ramadan di masa kecilnya. Nostalgia ibadah puasa Ramadan yang direpresentasikan oleh tokoh mengambil latar waktu pada tahun 90 -an. Komik ini dapat dikategorikan sebagai sindiran terhadap remaja saat ini, yang melakukan ibadah puasa Ramadan dengan banyak menghabiskan waktunya dengan kegiatan seperti bermain gadget dan menonton televisi. Berbeda dengan remaja tahun 90-an yang menjalan ibadah puasa Ramadan dengan aktivitas yang mengandung nilai-nilai pendidikan keagamaan, seperti mengikuti festival keagamaan dan kajian religi di bulan Ramadan.

Sejauh ini serial komik "Nostalgia Ramadhan Si Juki Kecil" karya Faza Meonk belum pernah dikaji oleh peneliti lainnya. Adapun artikel yang berkaitan dengan nilai-nilai pendidikan ibadah puasa Ramadan adalah sebagai berikut. Pertama oleh Mukmin (2017) dengan judul "Nilai-Nilai Pendidikan dalam Ibadah Puasa (Studi Analisis terhadap Surat Al-Baqarah Ayat 183-187)". Hasil penelitiannya menyimpulkan bahwa bentuk nilai pendidikan yang terkandung dalam ibadah puasa yaitu membentuk karakter kerja keras, kejujuran, kesabaran, disiplin, kesetaraan, rasa syukur, belajar menuntut ilmu pengetahuan, dan meningkatkan rasa empati terhadap orang lain. Kedua oleh Andrian (2018) dengan judul "Nilai-Nilai Pendidikan 
Islam dalam Pengalaman Puasa

Ramadhan Menurut Tafsir Al-Misbah".

Hasil penelitiannya menunjukkan bahwa nilai-nilai pendidikan yang terdapat dalam puasa Ramadan ialah meningkatkan kepekaan sosial, disiplin, jujur, dan sabar.

Artikel sebelumnya dan artikel ini memiliki kesamaan pada aspek kajian, yaitu nilai-nilai pendidikan ibadah puasa Ramadan dalam perspektif agama Islam. Adapun yang membedakannya ada pada sumber data. Artikel sebelumnya fokus terhadap studi lapangan, sedangkan artikel ini menggunakan karya sastra. Selain itu, artikel sebelumnya hanya menguraikan makna dalam ibadah puasa Ramadan, sementara artikel ini mengungkapkan bentuk kegiatan yang mengandung makna nilai-nilai pendidikan keagamaan.

Berdasarkan uraian di atas, tujuan artikel ini adalah mendeskripsikan nilainilai pendidikan puasa Ramadan dalam komik webtoon "Nostalgia Ramadhan $\mathrm{Si}$ Juki Kecil” karya Faza Meonk.

\section{Landasan Teori}

\subsection{Pragmatik}

Pragmatik sastra merupakan cabang penelitian yang mengarahkan kepada bagaimana hakikat kegunaan sastra (Endrawara, 2013: 115). Adapun pendekatan pragmatik dalam analisis sebuah karya sastra merupakan pendekatan yang memfokuskan terhadap tanggapan pembaca sebagai penikmat karya sastra (Ratna, 2013: 71). Pembaca dalam perspektif pragmatik memiliki peranan penting terhadap keberadaan sastra (Siswanto, 2008: 190). Artinya, pembaca berperan dalam menentukan apakah termasuk karya sastra atau bukan.

Setiap pembaca memiliki latar belakang yang berbeda. Akibat hal tersebut, dalam penangkapan sebuah makna karya sastra juga akan memiliki perbedaan sesuai dengan pemahaman masing-masing pembaca. Menitikberatkan kajian berdasarkan pembaca ini semakin mendapatkan tempatnya melalui sifat sastra yang multitafsir sehingga memungkinkan untuk pembaca memperoleh banyak makna dan manfaat dari sebuah karya sastra (Gumono, 2017: 71).

\subsection{Nilai-nilai Pendidikan Puasa Ramadan}

Puasa Ramadan adalah salah satu ibadah dalam agama Islam yang memiliki hukum wajib, baik kepada laki-laki dan perempuan. Kewajiban melaksanakan puasa Ramadan sebagai wujud ketakwaan kepada Allah, seperti 
menahan lapar, haus, dan hawa nafsu (Nareswari, 2014: 16). Apabila seorang muslim tidak melaksanakan puasa pada bulan Ramadan baik disengaja atau tidak, maka seorang muslim tersebut wajib untuk menggantinya di bulan lain. Secara umum puasa adalah menahan diri dari nafsu, makan dan minum, dan segala sesuatu yang dapat membatalkan puasa mulai dari terbit fajar sampai tenggelam matahari. Adapun menurut Imam Al-Ghazali (Sudarto, 2018: 78), puasa adalah menahan segala sesuatu hal yang masuk ke dalam kerongkongan dan tidak melakukan kegiatan seksual. Ada beberapa hal yang dapat membatalkan puasa, yaitu makan, minum, dan menyedot sesuatu melalui hidung.

Puasa melatih seseorang dalam manajemen hawa nafsu duniawi, melatih sikap sabar, dan melatih cara berpikir yang sehat dan mengasah kecerdasan (Arifin, 2013: 79). Oleh karena itu, dengan berpuasa membantu seseorang terhindar dari perbuatanperbuatan yang tidak baik terutama dalam hal kerakusan dan kesombongan. Dalam melaksanakan ibadah puasa, seseorang diajarkan untuk dapat menahan diri dari segala bentuk nafsu manusia yang dapat membatalkan puasa.

Pengendalian diri adalah sebuah usaha untuk tidak melakukan sesuatu sesuai dengan keinginannya secara berlebihan. Dalam pengendalian diri mengandung sebuah kesabaran yang notabene sabar itu merupakan bagian dari puasa. Untuk menuju kesabaran dalam pengendalian diri, pasti dilandasi oleh niat. Niat adalah perbuatan yang diniatkan kepada Allah Swt. karena sudah iman atau percaya bahwa dengan berpuasa akan membawa seseorang pada kedudukan bertakwa dan siap menerima segala perintah dari Allah Swt. (Andy, 2018: 6).

Ramadan adalah salah satu bulan pada kalender hijriah yang istimewa dari bulan yang lainnya. Ramadan istimewa karena di dalam bulan ini banyak sekali nilai positif, baik untuk hubungan antara manusia sekaligus hubungan manusia dengan Allah. Nilai-nilai positif tersebut terdiri atas nilai pendidikan, kepedulian sosial, dan kepekaan seorang hamba terhadap perintah Allah.

Nilai pendidikan adalah sebuah usaha secara sadar yang terencana dalam proses pembelajaran untuk membentuk etika, moral, dan budi 
pekerti kepada setiap orang untuk diterapkan dalam masyarakat, bangsa, dan negara (Sukitman, 2016: 87). Dengan adanya nilai pendidikan akan membantu orang tua untuk membentuk karakter anak yang sesuai dengan norma dalam masyarakat. Nilai pendidikan bisa diterapkan kepada anak melalui ibadah puasa Ramadan. Menurut Quraish Shihab (Andrian, 2018), ada beberapa nilai pendidikan yang terkandung dalam ibadah puasa Ramadan, di antaranya adalah kejujuran, kesabaran, kedisiplinan, dan kepekaan sosial.

\subsubsection{Kejujuran}

Jujur merupakan satu sifat yang mulia yang harus ada pada diri manusia. Dalam pandangan agama Islam, kejujuran merupakan suatu sikap bentuk penyesuaian antara berita dengan kenyataan, perbuatan dengan keyakinan, serta adanya kesungguhan dalam upaya apa yang dikehendaki (Shihab, 2002: 745). Sikap jujur dalam kehidupan bermasyarakat menjadi kunci utama, karena dengan kejujuran seseorang memperoleh kepercayaan dari orang lain sehingga dapat menjalin hubungan sosial yang baik.

Kejujuran merupakan investasi yang sangat berharga dalam kehidupan manusia karena kejujuran itu sendiri memberikan banyak manfaat untuk diri kita. Dengan adanya perilaku jujur menghantarkan manusia menuju ke jalan Allah. Sebagaimana janji Allah yang terkandung dalam QS. Al-Maidah ayat 119 yaitu surga bagi mereka yang beruntung. Orang yang beruntung tersebut salah satunya ialah orang yang memiliki perilaku jujur semasa hidupnya. Seseorang yang tidak memiliki perilaku yang bertentangan dengan kebenaran, maka Allah memberikan rida-Nya kepada orang yang memiliki perilaku demikian. Tentunya hal ini menjadi anugerah dan keuntungan yang begitu tinggi kedudukannya (Shihab, 2002: 255).

Kejujuran dalam ajaran Islam diterapkan dalam segala kehidupan seorang muslim, seperti pada saat melaksanakan ibadah puasa Ramadan. Dalam pelaksanaan ibadah puasa Ramadan, kejujuran terletak pada pelaksanaan ibadah puasa itu sendiri. Orang yang berpuasa, tidak ada yang mengetahui ia mengaku berpuasa tetapi minum saat berwudu, selain Allah dan kehormatan nurani kejujuran dalam diri manusia (Burhanudin, 2007: 40). Seseorang yang berpuasa itu menahan diri dari segala sesuatu yang dapat membatalkan puasa. Orang dengan 
keimanan yang lemah dan tingkat kejujuran yang rendah, maka mudah melakukan sesuatu yang membatalkan puasa karena merasa tidak ada yang mengetahuinya.

\subsubsection{Kedisiplinan}

Kedisiplinan merupakan sikap menaati peraturan dan ketentuan yang telah ditetapkan, melalui latihan batin dan watak untuk mencapai tujuan dengan maksimal (Shihab, 2016: 191). Adapun menurut (Hani, 2008: 17), kedisiplinan merupakan suatu hal yang mutlak pada manusia karena apabila seseorang tidak memiliki kedisiplinan yang kuat dalam hidupnya, hal tersebut dapat membahayakan diri dan lingkungan sekitarnya. Berdasarkan pendapat tersebut, sikap disiplin harus dimiliki oleh manusia agar setiap prinsip dan tujuan dalam hidupnya dapat berjalan dengan baik.

Setiap muslim harus memiliki sikap disiplin karena salah satu ciri orang yang beriman adalah disiplin dalam segala hal dengan tidak menyianyiakan waktu (Andrian, 2018: 203). Seseorang yang menyia-nyiakan waktu sesungguhnya termasuk orang-orang yang merugi di dunia dan akhirat. Untuk melatih kedisiplinan, seorang muslim dapat melakukannya dengan berpuasa.
Puasa membuat orang yang melaksanakannya memiliki sikap disiplin yang tinggi. Hal tersebut dapat dilihat dari hadis sebagai berikut.

"Berpuasalah kalian dengan melihatnya (hilal) dan berbukalah dengan melihatnya pula. Apabila kalian terhalang oleh awan maka sempurnakanlah jumlah bilangan bulan Sya'ban menjadi tiga puluh" (HR. Ibnu Umar RA)

Melalui kandungan hadis tersebut, seorang muslim diajarkan untuk disiplin dalam waktu pelaksanaannya. Selain itu, seorang muslim juga diajarkan untuk disiplin dalam mencegah perbuatan yang dapat membatalkan puasa.

\subsubsection{Kepekaan Sosial}

Manusia merupakan salah satu makhluk Tuhan yang memiliki jiwa sosial tinggi. Sikap empati tinggi sudah menjadi kewajiban bagi setiap manusia terutama kaum muslim. Dengan adanya kepedulian antara sesama manusia menunjukkan ketakwaan kepada Allah. Bentuk ketakwaan manusia kepada Tuhannya tidak hanya dilakukan dengan menyibukkan diri dengan beribadah kepada Allah saja melainkan juga harus memiliki kepekaan sosial yang tinggi (El-Hamdy, 2010: 232).

Rasa kepedulian sosial yang tinggi bagi seorang muslim dapat dilakukan dengan ibadah puasa. Dengan 
melakukan puasa, menahan lapar dan dahaga serta hawa nafsu duniawi, dapat meningkatkan kepekaan sosial terhadap sesama dan meningkat rasa syukur. Hal tersebut dipertegas oleh N. Syam (2018: 18) yang mengatakan bahwa salah satu fungsi dari puasa ialah dapat melatih kepekaan sosial terhadap kesusahan orang lain, seperti kurang makan, kasih sayang, dan harapan.

\section{Metode Penelitian}

Artikel ini termasuk penelitian kualitatif karena bertujuan menggambarkan nilai-nilai pendidikan puasa Ramadan dalam komik webtoon "Nostalgia Ramadhan Si Juki Kecil" karya Faza Meonk, dengan cara deskriptif dalam bentuk kata-kata. Adapun metode yang digunakan dalam artikel ini adalah metode analisis isi kualitatif karena ingin mengungkapkan aspek pragmatik dalam karya yang dianalisis. Menurut Ratna (Nisdawati, 2019: 18), metode analisis isi merupakan metode yang digunakan untuk menganalisis isi teks dan makna dalam karya sastra, seperti pesan moral, nilai pendidikan, dan nilai budaya.

Sumber data artikel ini adalah komik webtoon "Nostalgia Ramadhan Si Juki Kecil” karya Faza Meonk. Data berupa kalimat dan dialog yang menggambarkan nilai-nilai pendidikan puasa Ramadan. Teknik pengumpulan data dengan cara sebagai berikut, (1) membaca secara keseluruhan teks cerita komik "Nostalgia Ramadhan Si Juki Kecil", (2) mengidentifikasi data yang mencerminkan nilai-nilai pendidikan puasa Ramadan, dan (3) mencatat data yang diperoleh dari komik webtoon "Nostalgia Ramadhan Si Juki Kecil". Adapun, teknik analisa data yang dilakukan dalam artikel ini yaitu, (1) mengklasifikasi data sesuai dengan rumusan masalah, (2) menganalisis data, (3) menginterpretasikan data, dan (4) penarikan kesimpulan. Validasi data dengan cara (1) ketekunan pengamatan yang dilakukan untuk menemukan data yang relevan dengan rumusan masalah, dan (2) berdiskusi dengan beberapa ahli.

\section{Pembahasan}

Hasil artikel ini menunjukkan bahwa komik webtoon "Nostalgia Ramadhan Si Juki Kecil” menggambarkan nilai-nilai pendidikan puasa Ramadan seperti, (1) nilai pendidikan puasa Ramadan dalam aspek kejujuran, (2) nilai pendidikan puasa Ramadan dalam aspek kedisiplinan, dan (3) nilai pendidikan puasa Ramadan 
dalam aspek kepekaan sosial. Hal tersebut dijelaskan sebagai berikut.

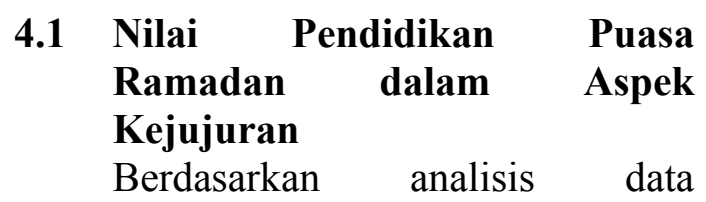
ditemukan nilai pendidikan dalam aspek kejujuran terletak pada pelaksanaan ibadah puasa Ramadan yang dilakukan oleh tokoh Juki. Hal tersebut dapat dilihat sebagai berikut.

\subsubsection{Takut untuk Melakukan Perbuatan Mencuri}

Konsep perilaku jujur menurut Shihab (2002: 745), adalah bentuk penyesuaian dari perkataan dengan kenyataan dan perilaku dengan keyakinan. Adanya keyakinan untuk bersikap jujur, menjauhkan seseorang untuk tidak melakukan perbuatan yang dilarang oleh Allah, salah satunya perbuatan mencuri. Hal tersebut dilakukan oleh tokoh Juki dalam kutipan berikut.

"wah mangganya udah mateng tuh Boy!"

"Wih iya! Lumayan buat buka!"

Juki: tapi kan kita belom minta.

Teman Juki: ah nggak apa apa! Ku coba ketapel nih ya!

Juki: gue nggak ikut-ikutan kalo kena marah pak Haji ya!

Teman Juki: nah berarti jatah Juki buat aku! (Meonk, 2015, Chapter 3)

Kutipan di atas menggambarkan interaksi tokoh Juki dan temannya.
Teman Juki mengajak Juki untuk mencuri mangga dari perkebunan milik Pak Haji. Akan tetapi, tanggapan yang diberikan Juki adalah menolak untuk tidak melakukan perbuatan yang dilarang oleh Allah. Perbuatan Juki mencerminkan nilai kejujuran dalam bertutur kata dan berperilaku dalam kehidupan masyarakat.

Pelaksanaan sikap jujur yang dicerminkan oleh tokoh Juki memberikan makna bahwa pentingnya sikap jujur untuk menciptakan lingkungan sosial yang kondusif. Adanya tindakan penolakan Juki untuk mencuri karena kesadaran bahwa perbuatan mencuri bertentangan dengan kebenaran atau kejujuran yang dapat menimbulkan permusuhan antara sesama. Selain itu, mencuri merupakan tindakan yang dilarang dalam agama Islam dan dapat menggugurkan ibadah puasa.

\subsubsection{Keberanian sebagai Bentuk Kejujuran \\ Sebagaimana pendapat Tasmara} (2001: 190), indikator perilaku jujur adalah berani mengambil resiko atas perbuatan yang dilakukan. Hal tersebut digambarkan oleh tokoh Juki yang berani berkata jujur kepada ibunya dalam pelaksanaan ibadah puasa Ramadan. 
Juki: mak sebenarnya tadi juki udah buka. Di paksa air keran! Lemesnya Cuma pura-pura!

Emmak: oh ya udah, yang penting jangan juki udah jujur dan janji nggak ngulangin lagi.

Juki: ngoaaaaa terima kasih mak (Meonk, 2016, Chapter 5).

Kutipan di atas menjelaskan sikap keberanian tokoh Juki untuk berkata jujur kepada Emaknya. Tokoh Juki berani mengambil risiko dimarahi oleh Emaknya dengan mengakui bahwa puasa yang dilakukan telah batal karena meminum air keran. Perilaku tersebut tentu bukanlah menjadi perkara yang mudah bagi setiap individu karena di dalamnya dibutuhkan keberanian yang kuat untuk menerima risiko dari perbuatan yang dilakukan.

Berdasarkan kutipan di atas, tokoh Juki mencerminkan perilaku jujur dengan bentuk berani berkata jujur/mengambil risiko dimarahi oleh Emaknya. Sikap jujur sangat penting ditanamkan sejak usia dini. Dengan demikian, dapat membentuk tumbuh kembang anak yang baik, memiliki moralitas yang sesuai dengan nilai-nilai pendidikan keagamaan dan normanorma luhur. Sikap jujur yang ditanamkan pada anak sejak dini menjadi modal terhadap anak untuk hidup dalam masyarakat dengan baik (Inten, 2017: 36).

\subsection{Nilai Pendidikan Puasa Ramadan dalam Aspek Kedisiplinan \\ Berdasarkan analisis data}

ditemukan bentuk kegiatan dalam puasa Ramadan yang mencerminkan nilai-nilai pendidikan puasa Ramadan dalam aspek kedisiplinan, yaitu sebagai berikut.

\subsubsection{Sahur dan Buka Puasa}

Dalam melaksanakan ibadah puasa Ramadan, salah satu kegiatan yang wajib dilakukan oleh umat muslim adalah sahur dan buka puasa. Sahur merupakan latihan untuk membentuk karakter disiplin seseorang (Herwibowo \& Yasin, 2009: 212). Sementara, karakter disiplin juga terbentuk melalui kesabaran seseorang menahan dahaga dan rasa lapar sampai waktu magrib (berbuka puasa). Adapun dalam komik webtoon "Nostalgia Ramadhan Si Juki Kecil" karya Faza Meonk terdapat kegiatan sahur dan berbuka puasa yang mencerminkan nilai pendidikan kedisiplinan, dapat dilihat pada kutipan berikut.

(1) Babe: belum bangun Si Juki? Mama: belum nih beh...susah banget!

Babe: ya udah lah...biarin aja. Suruh besok aja puasanya! Mama: gak boleh gitu beh, juki harus belajar puasa mulai hari ini. Belajar ibadah. Jangan 
ditunda-tunda (Meonk, 2015, Chapter 1).

(2) Mak: Juki... udah belum? Udah adzan maghrib loh, waktunya buka!

Juki: ngoaaa... bentar mak... masih sakit perutt...! (Meonk, 2015, Chapter 3).

Kutipan di atas menjelaskan bagaimana kedisiplinan terbentuk melalui latihan dalam melaksanakan puasa Ramadan, seperti kegiatan sahur dan berbuka puasa. Menurut Quraish Shihab (Andrian, 2018), melalui puasa seseorang dilatih kedisiplinan. Data pertama menggambarkan terjadi interaksi antara tokoh Babeh dan Emak yang berusaha membangunkan Juki untuk melakukan sahur sebagai persiapan puasa. Data kedua menggambarkan kegiatan buka puasa yang dilakukan oleh tokoh Emak dan Juki yang sudah menahan dahaga dan lapar sampai waktu magrib.

Data tersebut mencerminkan pola asuh orang tua yang menanamkan pendidikan karakter kedisiplinan terhadap anak melalui puasa Ramadan. Syam (2017) mengatakan bahwa pada bulan Ramadan seseorang membiasakan makan, minum, dan tidur dengan teratur. Hal tersebut mencerminkan sikap kedisiplinan.
Sikap kedisiplinan sangat esensial dalam diri manusia untuk membentuk moral yang berkualitas. Kedisiplinan juga sebagai nilai dasar spiritual yang menjadikan manusia lebih dekat dengan Allah (Khoirunnisa, 2017: 42). Oleh karena itu, kedisiplinan penting ditanamkan dalam diri manusia sejak dini. Upaya pembentukan kedisiplinan terhadap anak dapat dilakukan oleh orang tua sebagai bagian dari tripusat pendidikan.

\subsubsection{Pesantren Kilat di Masjid}

Pesantren kilat merupakan kegiatan yang dilakukan pada bulan Ramadan. Tujuan kegiatan tersebut untuk mengisi kegiatan bulan Ramadan dengan hal-hal yang bermanfaat dan meningkatkan kecerdasan spiritual bagi orang dewasa maupun anak-anak. Dalam komik webtoon "Nostalgia Ramadhan Si Juki Kecil" karya Faza Meonk terdapat kegiatan pesantren kilat yang mencerminkan pendidikan kedisiplinan bagi anak-anak. Hal itu dilihat pada kutipan berikut.

"seperti biasa, tiap siang menjelang sore ada pesantren kilat di masjid saat ramadhan"

Ustaz: Alhamdulillah, pengajian hari ini selesai. Oh iya, buku kegiatan ramadhan kalian sudah di isi anak-anak? Pak ustad ingin periksa agar nanti kalau sudah 
masuk sekolah kalian tidak dimarahi guru agama.

Juki: waduh!

Bedil: ada apa juki? Kok panik gitu?

Juki: gimana nih dil, Juki lupa ngisi dari hari pertama puasa (Meonk, 2016, Chapter 6).

Kutipan di atas menggambarkan kegiatan pesantren kilat di masjid setiap sore pada bulan Ramadan. Dalam kegiatan tersebut, tokoh Ustaz meminta kepada murid-muridnya untuk mengumpulkan catatan terhadap aktivitas selama bulan Ramadan. Hal tersebut mencerminkan tindakan yang dilakukan Ustaz yang berusaha mendidik murid-muridnya dalam melatih kedisiplinan dengan cara mencatat apa yang telah diperbuat selama bulan puasa. Hasil catatan dari murid-murid akan dijadikan sebagai bahan evaluasi, baik dalam pendidikan formal (sekolah) maupun nonformal (pesantren kilat).

Pesantren kilat yang dilakukan oleh tokoh di atas sebagai sarana pembentukan kedisiplinan terhadap anak-anak. Rahayu et al. (2019: 5) mengatakan bahwa kegiatan keagamaan, salah satunya adalah pesantren kilat, dapat meningkatkan kedisplinan siswa dalam beribadah, membaca Al-Qur'an setiap hari, menambah wawasan keagamaan, dan meningkatkan moralitas yang baik.

\subsection{Nilai Pendidikan Puasa Ramadan dalam Aspek Kepekaan Sosial \\ Berdasarkan analisis data \\ ditemukan bentuk kegiatan dalam} puasa Ramadan yang mencerminkan nilai-nilai pendidikan puasa Ramadan dalam aspek kepekaan sosial, yaitu sebagai berikut.

\subsubsection{Ngabuburit}

Tradisi umat muslim pada bulan puasa Ramadan salah satunya adalah ngabuburit. Kata ngabuburit berasal dari bahasa Sunda, yaitu burit yang memiliki arti sore menjelang malam. Dengan demikian, ngabuburit merupakan aktivitas masyarakat di sore hari dengan tujuan menunggu buka puasa (R, n.d.: 76). Kegiatan ngabuburit dilakukan oleh orang dewasa sampai anak-anak, seperti bermain permainan tradisonal.

Dalam komik webtoon "Nostalgia Ramadhan Si Juki Kecil” karya Faza Meonk terdapat kegiatan ngabuburit yang dilakukan oleh tokoh yang mencerminkan nilai pendidikan puasa Ramadan pada aspek kepekaan sosial. Hal itu dibuktikan pada kutipan berikut. 
(1)“waktu kecil dulu, gue dan teman-teman suka ngabisin waktu untuk nunggu berbuka sambil main bambu, atau sering di sebut bedil"

"bedil ini mainan tradisional, dimana bambu yang di lubangi bagian pangkalnya, kemudian di sulut api dan akan menghasilkan bunyi kayak meriam! (Meonk, 2015, Chapter 6).

(2)“waktu kecil dulu gue sering banget main petak umpet saat nunggu berbuka" (Meonk, 2016, Chapter 8).

Kutipan di atas menggambarkan aktivitas tokoh Juki dan temantemannya melakukan ngabuburit dengan bermain permainan tradisional, seperti bedil dan petak umpet. Permainan tradisional "petak umpet" merupakan permainan yang dilakukan dua orang atau lebih, yang memiliki misi menemukan pemain yang bersembunyi (Muzayanah, 2017: 142). Manfaat permainan tradisonal petak umpet dapat melatih kepekaan sosial anak (Hananta \& Mas'udah, 2015: 5).

Sikap kepekaan sosial merupakan cerminan dari nilai pendidikan ibadah puasa Ramadan. Seseorang yang melakukan ibadah puasa yang diniatkan karena Allah, dapat melatih sikap solidaritas yang tinggi terhadap orang lain. Solidaritas yang tinggi terhadap sesama, sangat penting dalam kehidupan masyarakat.

\subsubsection{Salat Id dan Silaturahmi}

Kegiatan puncak dalam puasa Ramadan adalah salat Id dan silaturahmi. Salat Id merupakan salat

yang dilaksanakan secara bersama-sama oleh umat muslim dengan tujuan melatih kepekaan sosial dan menjaga persatuan (Yunta, 2019: 60). Sementara silaturahmi merupakan usaha untuk menjalin tali persaudaraan yang harmonis (Mariana \& Nurmilah, 2012: 26). Bentuk silaturahmi dapat diungkapkan dengan beberapa cara, seperti menyapa, mengunjungi, dan menanyakan kabar.

Dalam komik webtoon "Nostalgia Ramadhan Si Juki Kecil" karya Faza Meonk terdapat kegiatan salat Id dan silaturahmi yang digambarkan oleh tokoh. Aktivitas tersebut mencerminkan nilai pendidikan puasa dalam aspek kepekaan sosial. Hal itu dapat dilihat pada kutipan berikut.

“akhirnya lebaran tiba juga! Yang nggak mau gue lewatkan tiap lebaran adalah solat ied"

"dan yang pasti, makan sepuasnya! Ngoahahaha!"

Juki: nyam, nyam enaknyaa kue lebaran.

Babe: Juk, ayo salam salaman dulu 
"ya, sebelum keliling ke rumah saudara dan kerabat, biasanya kita maaf-maafan dulu di rumah"

Lela: Emak, maafin Lela yaa.

Indra: maafin indra ya Beh.

Juki: ngoee hiks! Maafin Juki

Beh, maafin segala kesalahan

Juki!

Babe: iyah Juki, gak usa nangis, babeh pasti maafin kok!

Juki: tapi juki banyak salah sama Babeh.

Babeh: tenang ajah, semua kesalahan Juki Babeh maafin kok (Meonk, 2016, Chapter 13).

\section{Penutup}

Berdasarkan hasil analisis di atas dapat disimpulkan nilai-nilai pendidikan puasa Ramadan yang terdapat dalam komik webtoon "Nostalgia Ramadhan Si Juki Kecil” karya Faza Meonk adalah sebagai berikut. (1) Nilai pendidikan puasa Ramadan dalam aspek kejujuran dapat dilihat dalam pelaksanaan puasa. Nilai pendidikan pada aspek kejujuran sangat penting ditanamkan sejak usia dini, agar anak-anak memiliki moralitas yang baik (bertanggung jawab) dan dapat diterapkan dalam lingkungan sehari-hari. (2) Nilai pendidikan puasa Ramadan dalam aspek kedisiplinan dapat dilatih melalui kegiatan sahur dan buka puasa dan kegiatan pesantren kilat di masjid. Nilai pendidikan kedisiplinan dalam kehidupan sehari-hari memiliki peranan penting untuk mendekatkan diri
Data di atas menjelaskan kegiatan silaturahmi yang dilakukan tokoh sebagai wujud kesadaran emosional dalam diri seseorang untuk saling memaafkan satu sama lain. Dengan saling memaafkan, akan tercipta hubungan yang baik dalam lingkungan keluarga maupun masyarakat. Kegiatan salat Id dan silaturahmi merupakan rangkaian kegiatan yang tidak dapat dipisahkan dalam suasana Idulfitri. dengan Allah, dan mengasah kecerdasan spiritual seseorang. (3) Nilai pendidikan puasa Ramadan dalam aspek kepekaan sosial, dapat dilatih melalui kegiatan ngabuburit dan kegiatan salat Id dan silaturahmi. Nilai pendidikan kepekaan sosial dalam diri seseorang berperan dalam mewujudkan hubungan yang baik dengan sesama, sebagai wujud ketakwaannya kepada Allah.

Keduanya sangat penting untuk mendidik seseorang memiliki rasa empati yang tinggi terhadap orang lain. Hal tersebut, selaras dengan pemikiran Mariana \& Nurmilah (2012: 6) yang mengatakan bahwa melalui silaturahmi dapat mengasah kepekaan sosial dan mendapatkan rahmat dari Allah. 


\section{Daftar Pustaka}

Andrian, B. (2018). Nilai-Nilai Pendidikan Islam dalam Pengamalan Puasa Ramadhan Menurut Tafsir Al-Misbah. Lampung: Universitas Islam Negeri Raden Intan Lampung.

Andy, S. (2018). Hakikat Puasa Ramadhan dalam Perspektif Tasawuf (Tafsir Q.S Al-Baqarah: 183). Jurnal Ibn Abbas, 1-17. https://doi.org/10.9876/jia.v1i1.189 5

Ardias, A. Y., Sumartini, \& Mulyono. (2019). Konflik Sosial Dalam Novel Karena Aku Tak Buta Karya Rendy Kuswanto. Jurnal Sastra Indonesia, 8 (1), 47-56. https://doi.org/10.15294/jsi.v8i1.29 949

Arifin, A. (2013). Step By Step Fiqih Puasa Edisi Revisi. Jakarta: Elex Media Komputindo.

Burhanudin, Y. (2007). Misteri Bulan Ramadhan (2nd ed.). Jakarta: Qultummedia.

El-Hamdy, U. (2010). Rahasia Kedahsyatan Puasa Senin Kamis. Jakarta Selatan: Wahyu Media.

Endrawara, S. (2013). Metodologi Penelitian Sastra. Yogyakarta: CAPS.

Gumono, A. T. (2017). Analisis Film Denias dengan Pendekatan Pragmatik. Polyglot, 13 (1), 69-78.

Gunandha, R., \& Aditya, R. (2020). Keji! Youtuber Ferdian Paleka Prank Waria Kasih Sembako Isi Batu dan Sampah. Retrieved from Suara.com https://www.suara.com/news/2020/ 05/03/172448/keji-youtuberferdian-paleka-prank-waria-kasihsembako-isi-batu-dan-sampah

Hananta, R. W., \& Mas'udah. (2015). Pengaruh Permainan Petak Umpet Terhadap Kemampuan Sosial Emosional Anak. PAUD Teratai, 4 (2), 1-6.

Hani. (2008). Strategi Pengembangan Kedisiplinan di Madrasah Ibtidaiyah Negri. UIN Maliki Malang.

Herwibowo, B., \& Yasin, A. H. (2009). Menjadi Kesayangan Allah-The Power of Akhlak. Jakarta Selatan: Qultummedia.

Inten, D. N. (2017). Penanaman Kejujuran Pada Anak Dalam Keluarga. Jurnal FamilyEdu, 3 (1), 35-45.

Khoirunnisa, R. (2017). Pengembangan Spiritual sebagai Upaya Guru Bimbingan dan Konseling untuk Meningkatkan Kedisiplinan Siswa. Hisbah, 14 (1), 38-49.

Mariana, A., \& Nurmilah, M. (2012). Inilah Pesan Penting di Balik Berkah \& Manfaat Silaturahmi. Bandung: Ruang Kata.

Meonk, F. (2015). Nostalgia Ramadhan Si Juki Kecil. Retrieved from Line Webtoon website: https://www.webtoons.com/id/com edy/ramadhan-bersama-si-jukikecil/list?title no $=496 \&$ page $=2$

Meonk, F. (2016). Nostalgia Ramadhan Si Juki Kecil Season2. Retrieved from Line Webtoon website: https://www.webtoons.com/id/com 
edy/si-juki-

ramadhan/list?title_no $=688 \&$ page $=$ 2

Mukmin, T. (2017). Nilai-Nilai Pendidikan dalam Ibadah Puasa (Studi Analisis terhadap Surat AlBaqarah Ayat 183-187). El-Ghiroh, 12 (1), 42-67.

Muzayanah, U. (2017). Peningkatan Keaktifan dan Hasil Belajar IPS melalui Permainan Petak Umpet pada Siswa Kelas VIIB Semester Genap SMP Negeri 2 Wedarijaksa Tahun Pelajaran 2016/2017. Forum Ilmu Sosial, 44 (2), 141-147. https://doi.org/10.15294/fis.v44i2.1 5582

Nareswari, M. K. (2014). Dosa-dosa yang Tak Disadari Wanita: Karena biasa, bukan berarti tak berdosa (M. Pressindi, Ed.). Yogyakarta.

Nata, A. (2016). Pendidikan dalam Perspektif Al-Qur'an. Jakarta: Prenada Media.

Nisdawati. (2019). Nilai-Nilai Tradisi Dalam Koba Panglimo awang: : Masyarakat Melayu Pasir Pengaraian. Yogyakarta: Deepublish.

Putri, D. S. (2016). Trauma Tokoh Nakajima dalam Komik Ouroboros Karya Kanzaki Yuya. Universitas Andalas.

R, A. Y. (n.d.). Ajaibnya Puasa: Fasting is Amazing. Bandung: DAR! Mizan.

Rahayu, W., Triwoelandari, R., \& Gustiawati, S. (2019). Analisis Program Kegiatan Keagamaan terhadap Peningkatan Akhlak Siswa (Studi Kasus MTsN Kota
Bogor). Jurnal Pendidikan \& Pengajaran Guru Sekolah Dasar, 2 (1), 01-06. https://doi.org/10.33751/jppguseda. v2i1.995

Ratna, N. K. (2013). Teori, Metode, dan Teknik Penelitian Sastra dari Strukturalisme hingga Postrukturalisme Perspektif Wacana Naratif. Yogyakarta: Pustaka Pelajar.

Setyawan, D. (2018). Analisis Kepribadian dan Emosi Tokoh Utama Tadakuni dalam Komik Danshi Koukousel No Nichijou Karya Yasunobu Yamauchi. Universitas 17 Agustus 1945.

Shihab, M. Q. (2002). Tafsir AlMishbah: Pesan, Kesan, dan Keserasian Alquran. Jakarta: Lentera Hati.

Shihab, M. Q. (2016). Akhlak: yang Hilang dari Kita. Tanggerang: Lentera Hati.

Siswanto, W. (2008). Penghantar Teori Sastra. Jakarta: Grasindo.

Sudarto. (2018). Ilmu Fikih (Refleksi Tentang: Ibadah, Muamalah, Munakahat dan Mawaris). Yogyakarta: Deepublish.

Sukitman, T. (2016). Internalisasi Pendidikan Nilai dalam Pembelajaran (Upaya Menciptakan Sumber Daya Manusia yang Berkarakter). Jurnal Pendidikan Sekolah Dasar, 2 (3), 85-96.

Sukiyat. (2020). Strategi Implementasi Pendidikan Karakter. Surabaya: Jakad Media Publishing.

Syafril, \& Zen, Z. (2019). Dasar-Dasar 
Nilai-Nilai Pendidikan Puasa Ramadan...

Ilmu Pendidikan. Depok: Prenada Media.

Syam, N. (2018). Demi Agama, Nusa dan Bangsa. Jakarta: Prenada Media.

Syam, Y. H. (2017). Materi Puasa Ramadhan: Elmatera. Yogyakarta: Diandra Kreatif.
Tasmara, T. (2001). Kecerdasan Ruhaniah. Jakarta: Gema Insani Press.

Yunta, A. H. D. (2019). Tinjauan Hukum Pelaksanaan Salat ID di Beberapa Masjid yang Berdekatan dalam Satu Wilayah. Nukhbatul'ulum, 5 (1), 54-63. 